\title{
Monthly average daily diffuse solar radiation in Poland within the period 2005-2015
}

\author{
Małgorzata Kleniewska ${ }^{l, *}$, Dorota Mitrowska ${ }^{l}$, Bogdan H. Chojnicki
}

\begin{abstract}
${ }^{1}$ Division of Meteorology and Climatology, Faculty of Civil and Environmental Engineering, Warsaw University of Life Science, Nowoursynowska 166, 02-787 Warsaw, Poland

${ }^{2}$ Department of Meteorology, Faculty of Environmental Engineering and Spatial Management, Poznań University of Life Sciences, 60-649 Poznań, Poland
\end{abstract}

\begin{abstract}
In this paper an 11-year series of daily values of diffuse solar radiation registered at 8 actinometric stations in Poland was used to describe the characteristics of diffuse radiation and diffuse fraction of global radiation for the area of Poland. Based on the monthly average daily diffuse, global and extraterrestrial solar radiation a linear relationship between these elements was determined. The obtained equation enables the calculation of the monthly average daily diffuse solar radiation for Poland and the application of its values to further climatology studies.
\end{abstract}

\section{Introduction}

The estimation of the amount of total solar radiation $(\mathrm{H})$, its structure (the share of beam and diffuse radiation), temporal and spatial variations and their reasons are essential for a number of research areas, such as topoclimatology [1], agriculture [2] or sustainable technologies [3]. The amount and structure of incoming solar radiation depend on extraterrestrial radiation and on its absorption and dispersion by clouds, aerosols and gases.

The flux of solar energy which reaches Earth in a diffuse form (D) has not been explored as thoroughly as total solar radiation, which is due to a lesser availability of measurement results, among other things. However, available references recognise the importance of diffuse solar radiation for ecosystems, indicating an enhanced performance of photosynthesis in diffuse radiation [4] and its influence on evapotranspiration [5-7]. At the same time, changes in cloudiness and the quantity of natural and anthropogenic aerosols cause changes in the amount of total radiation and its structure $[8,9]$. This may consequently lead to changes in the exchange of carbon dioxide between the atmosphere and the surface, and global changes in the efficiency of ecosystems and the land carbon sink. The published results of research in Poland into diffuse solar radiation are limited. Bryś stated that in Wroclaw in the middle of $70 \mathrm{~s}$ diffuse solar radiation trends changed from raise to fall phase [10]. In total solar radiation analysis in Poland, depending on station and the length of the time series, different trends were detected. In Wrocław, during the years 1875-2010 significant, negative trend of $\mathrm{H}$ was found. In Kraków the long-term (1884-2010) pattern of yearly amounts of total radiation is sinusoidal in shape and demonstrates slightly decreasing radiation values for the entire heliographic series [11]. During the period from 1964 to 2013 a statistically non-significant decrease in total solar radiation in Kolobrzeg [12] and increase in Warsaw was observed [13]. In Warsaw, there are two opposite, statistically significant trends were observed in the analyzed total solar radiation series: the decrease in the years 1964-1981 and an increase of $\mathrm{H}$ from 1984 to 2013 [13].

In Poland, the number of stations where diffuse solar radiation is measured is very limited, therefore it is important to seek other sources of information about $\mathrm{D}$, for example, by modelling its values on the basis of more common observations available. Diffuse radiation is modelled mainly from the relation between diffuse fraction $\left(D^{*}\right)$, which describes the share of diffuse radiation in total solar radiation $\left(D^{*}=D / H\right)$ and the value of the clearness index $(K)$, which describes the share of total radiation in extraterrestrial $(\mathrm{Ho})$ solar radiation $(\mathrm{K}=\mathrm{H} / \mathrm{Ho})[14$ 16]. Other models contain also other parameters which affect the amount of diffuse solar radiation reaching the Earth, such as solar altitude [17], air temperature and humidity [18].

The formula proposed by [15] is the following:

$$
\frac{\bar{D}}{\bar{H}}=c+d \frac{\bar{H}}{\overline{H_{0}}}
$$


where $\bar{D}, \bar{H}, \overline{H_{O}}$ are monthly average daily sums of diffuse, total and extraterrestrial solar radiation, respectively, and $\mathrm{c}$ and $\mathrm{d}$ are coefficients of regression. Page [15] worked out $\mathrm{c}$ and $\mathrm{d}$ coefficients for 10 stations situated between $40^{\circ} \mathrm{N}$ and $40^{\circ} \mathrm{S}$, and provided averaged values of linear equation regression coefficients for the analysed area: $\mathrm{c}=1.00$ and $d=-1.13$. Based for daily data from Warsaw (1961-1975) Podogrocki [16] proposed for Poland different regression coefficients depends on $\mathrm{K}$ value. In the present paper it was calibrated regression equation (1) coefficients $\mathrm{c}$ and $\mathrm{d}$ for the conditions prevailing in Poland. The investigation of the fit of the equation (1) with the Page's [15] proposed coefficients was also done.

\section{Method}

The coefficients $\mathrm{c}$ and $\mathrm{d}$ for the equation (1) were determined for selected actinometric stations. To that end, a database from the years 1988-2015 for Warszawa and Kołobrzeg and 2005-2015 for the rest of stations was used, containing the results of observations from 8 actinometric stations situated in different parts of Poland (Fig. 1, Table 1).

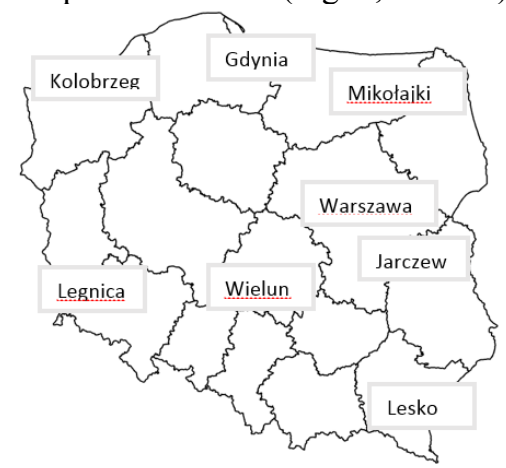

Fig. 1. Location of actinometric station.

The diffuse and total solar radiation measurements results were made available by the Institute of Meteorology and Water Management, National Research Institute (IMGW-PIB, https://dane.imgw.pl/) and World Radiation Data Centre (http://wrdc.mgo.rssi.ru/).

The stations were selected on the basis of the availability of a sufficiently representative sample and according to the station location (high mountain areas were not considered). The analysis was performed using daily sums of total, diffuse and extraterrestrial solar radiation, expressed in $\mathrm{MJ} \cdot \mathrm{m}^{-2}$. The daily values of extraterrestrial radiation were calculated for each day using R software [19] and the solaR package [20], as well as the method proposed by Michalsky et al. [21]. Model parameters were calibrated using the ratios of monthly average daily sums of extraterrestrial, total and diffuse solar radiation.

The daily values of $\mathrm{D}, \mathrm{H}$ and Ho were used to calculate their daily average values for each month. If data for 5 or more days was missing, the relevant month was not considered in further analysis. Table 1 contains the details of any missing data. The $\mathrm{c}$ and $\mathrm{d}$ parameters of the equation were determined using the least squares method in Excel with the Solver tool.

Table 1. Characteristics of stations and data set used in the analysis.

\begin{tabular}{|c|c|c|c|c|}
\hline Station & $\lambda(\mathbf{E})$ & $\varphi(\mathbf{N})$ & $\begin{array}{l}\text { Alt. } \\
{[\mathrm{m}]}\end{array}$ & Gaps \\
\hline Gdynia & $18^{\circ} 33^{\prime}$ & $54^{\circ} 31^{\prime}$ & 2 & $2005-2007$ \\
\hline Jarczew & $21^{\circ} 58^{\prime}$ & $51^{\circ} 48^{\prime}$ & 179 & $\begin{array}{c}\text { XI, XII.2005; } \\
\text { IX, X, XI } 2015\end{array}$ \\
\hline Kolobrzeg & $15^{\circ} 34^{\prime}$ & $54^{\circ} 11^{\prime}$ & 16 & - \\
\hline Legnica & $16^{\circ} 12^{\prime}$ & $51^{\circ} 11^{\prime}$ & 121 & VII,VIII 2007 \\
\hline Mikołajki & $21^{\circ} 35^{\prime}$ & $53^{\circ} 47^{\circ}$ & 140 & $\begin{array}{c}\text { IX.2005; } \\
\text { XI,XII } 2006\end{array}$ \\
\hline Warszawa & $20^{\circ} 58^{\circ}$ & $52^{\circ} 16^{\circ}$ & 130 & - \\
\hline Wieluń & $18^{\circ} 33^{\prime}$ & $51^{\circ} 12^{\prime}$ & 195 & X, XI, XII 2014 \\
\hline Lesko & $22^{\circ} 20^{\circ}$ & $49^{\circ} 27^{\circ}$ & 420 & $\begin{array}{l}\text { VI,VII, X } 2005 \text {, } \\
\text { II, X } 2006\end{array}$ \\
\hline
\end{tabular}

The obtained regression equation coefficients were averaged for the area of Poland to produce a single equation which described the relationship between $\mathrm{D}^{*}$ and $\mathrm{K}$. The fit of the equation was verified using series of independent data using the obtained model to calculate monthly averaged daily sums of diffuse radiation and comparing them with measured values. The actinometric stations were divided in two groups: the stations in Gdynia, Jarczew, Legnica and Wielun were used for the calibration, and Kołobrzeg, Mikołajki, Warszawa and Lesko were used for the to investigate the goodness of the estimation of diffuse solar radiation. Longer data series for Kołobrzeg and Warszawa allowed to check proposed model with the period different than used to calibration regression coefficients. An independent data series was also used to check the fit of the equation (1) with the coefficients proposed by [15]. Based on modelled and measured monthly average daily diffuse fraction and using coefficient of determination, $\mathrm{R}^{2}$, the goodness of the model itself was investigated. The goodness of the estimation of $\bar{D}$ was conducted using modelled and measured statistical parameters describing in [22, 23]:

-root mean square error, RMSE,

-mean absolute percentage error, MAPE,

-mean absolute bias error, MABE.

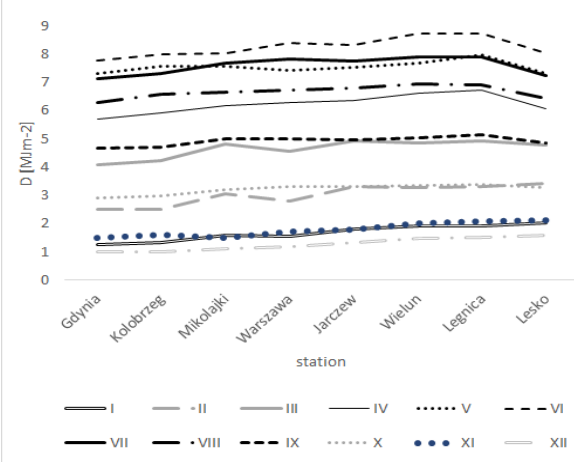

Fig. 2. Monthly averaged daily diffuse solar radiation in Poland in 2005-2015 


\section{Results}

\subsection{Monthly average daily sums of diffuse radiation}

The daily sums of diffuse radiation $(\bar{D})$ in Poland ranged - on average - from $1.3 \mathrm{MJ} \cdot \mathrm{m}^{-2}$ in December to $8.2 \mathrm{MJ}^{-2}$ in June; this kind of annual pattern with a minimum in December and a maximum in June was observed for each analysed station (Fig. 2).

The spatial distribution of $\bar{D}$ indicates lower values in the north part of Poland (Fig. 2). From May to September, the difference between mean value of $\bar{D}$ in Gdynia $\left(6.6 \mathrm{MJ} \cdot \mathrm{m}^{-2}\right)$ and Legnica $\left(7.3 \mathrm{MJ} \cdot \mathrm{m}^{-2}\right)$ was at approx. $10 \%$. In winter, on the other hand, the difference is much more visible and reached as much as $60 \%$ in January $\left(\bar{D}\right.$ in Gdynia was $1.25 \mathrm{MJ} \cdot \mathrm{m}^{-2}$, whereas in Wielun, Legnica and Lesko about $2 \mathrm{MJ} \cdot \mathrm{m}^{-2}$ ). The Lesko station is an exception here, because its greater values of $\bar{D}$ compared to the northernmost parts of Poland were observed only in the cold half of the year. This spatial variability is also evident when looking at the minimum values of $\bar{D}$ (Table 2), which fluctuated from $0.82 \mathrm{MJ} \cdot \mathrm{m}^{-2}$ in Kołobrzeg to $1.40 \mathrm{MJ} \cdot \mathrm{m}^{-2}$ in Lesko (Fig. 2, Table 2). The distribution of the maximum values of diffuse solar radiation shows a privileged position of the areas of central and south-western Poland: Legnica 9.57 $\mathrm{MJ} \cdot \mathrm{m}^{-2}$, Wieluń and Jarczew $9.3 \mathrm{MJ} \cdot \mathrm{m}^{-2}$, Warsaw $9.18 \mathrm{MJ} \cdot \mathrm{m}^{-2}$

Table 2. Minimum and maximum monthly average daily diffuse solar radiation $\left[\mathrm{MJ} \cdot \mathrm{m}^{-2}\right]$ during the period $2005-$

\begin{tabular}{|c|c|c|}
\hline \multicolumn{1}{|c|}{2015.} \\
\hline Station & $\overline{\boldsymbol{D}_{\min }}$ & $\overline{\boldsymbol{D}_{\max }}$ \\
\hline Gdynia & 0.90 & 8.75 \\
\hline Jarczew & 1.14 & 9.30 \\
\hline Kolobrzeg & 0.82 & 8.95 \\
\hline Legnica & 1.33 & 9.57 \\
\hline Lesko & 1.40 & 8.57 \\
\hline Mikolajki & 0.83 & 8.76 \\
\hline Warszawa & 0.97 & 9.18 \\
\hline Wielun & 1.24 & 9.33 \\
\hline
\end{tabular}

The annual value of the diffuse fraction $\mathrm{D}^{*}$ averaged for the 8 Polish stations, is 0.51 . In the warm part of the year (April - September) $\mathrm{D}^{*}$ is hardly varied between months $(0.39-0.42)$ and reaches 0.41 , whereas in the cold part of the year (October March), the variability is evident $(0.48-0.71)$ and the average value of $D^{*}$ is 0.61 (Fig. 3).

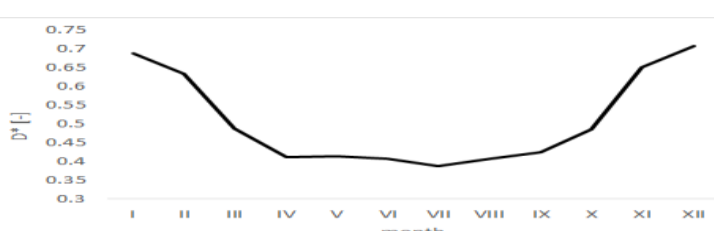

Fig. 3. Monthly average diffuse fraction in Poland in 2005 2015
The cold part of the year also demonstrates a greater variability of average and minimum values of $D^{*}$ between stations, in particular in December: the smallest $\mathrm{D}^{*}$ was observed for Lesko $(0.61)$ and the biggest in Kołobrzeg (0.80). Minimum values of $\mathrm{D}^{*}$ are hardly varied in Poland, ranging from 0.24 in Gdynia to 0.27 in Legnica, Wieluń and Mikołajki, whereas the variability of the maximum values ranged from 0.86 to 0.95 (Table 3). It is difficult to see a clear spatial variability of the monthly values of $\mathrm{D}^{*}$. The structure of $\mathrm{H}$ was examined for Warsaw by Podogrocki [16]. The mean value of $\mathrm{D}^{*}$ was 0.48 in the period of 1961-1975 and was smaller than for the period of 2005-2015 (Tab.3). For Warsaw we found lower mean monthly values of $\mathrm{D}^{*}$ from April to October, however in November, December and January D* were higher than for the period 1961 1975.

Table 3. Monthly average daily diffuse fraction in 2005 2015.

\begin{tabular}{|c|c|c|c|}
\hline Station & $\mathbf{D}_{\text {min }}^{*}$ & $\mathbf{D}_{\text {mean }}$ & $\mathbf{D}^{*}{ }_{\max }$ \\
\hline Gdynia & 0.24 & 0.50 & 0.86 \\
\hline Jarczew & 0.26 & 0.52 & 0.91 \\
\hline Kolobrzeg & 0.25 & 0.52 & 0.86 \\
\hline Legnica & 0.27 & 0.51 & 0.90 \\
\hline Lesko & 0.25 & 0.48 & 0.87 \\
\hline Mikolajki & 0.27 & 0.51 & 0.89 \\
\hline Warszawa & 0.26 & 0.53 & 0.95 \\
\hline Wielun & 0.27 & 0.50 & 0.92 \\
\hline
\end{tabular}

\subsection{Modelling monthly average daily diffuse solar radiation}

The calibration of the equation (1) for the conditions in Poland provided the linear regression coefficients $\mathrm{c}$ and $\mathrm{d}$, and the values of $\mathrm{R}^{2}$ for each 11-year series of observations (Table 4). The $\mathrm{R}^{2}$ of $0.86-0.94$ indicates a good fit of the model to the real data. The $\mathrm{c}$ is similar to the values obtained by [15], whereas $\mathrm{d}$ demonstrates a considerable deviation from values typical for the areas located between $40^{\circ} \mathrm{N}$ and $40^{\circ} \mathrm{S}$. Page [15] obtained - depending on the station - the values of $\mathrm{c}$ which ranged from 0.72 to 1.20 , while $\mathrm{d}$ ranged from -0.67 to -1.43 . Other authors' works also pointed out to different values of $\mathrm{c}$ and $\mathrm{d}$ for different locations, e.g. for Canada these amounted to 0.84 and -0.62 , respectively [24].

Table 4. Regression coefficients of linear regression between $\mathrm{D}^{*}$ and $\mathrm{K}$.

\begin{tabular}{|c|c|c|c|c|}
\hline Station & Gdynia & Jarczew & Wielun & Legnica \\
\hline $\mathrm{R}^{2}$ & 0.94 & 0.86 & 0.86 & 0.86 \\
\hline $\mathrm{C}$ & 1.06 & 1.12 & 1.10 & 1.10 \\
\hline $\mathrm{D}$ & -1.36 & -1.42 & -1.39 & -1.35 \\
\hline
\end{tabular}

The regression coefficients, averaged for all stations, reach 1.1 and -1.38 , therefore the formula which describes $\mathrm{D}^{*}$ for the area of Poland is the following: 


$$
\frac{\bar{D}}{\bar{H}}=1.1-1.38 \frac{\overline{\bar{H}}}{\overline{H_{0}}}
$$

The equation (1), including the coefficients determined by Page [11]: $\mathrm{c}=1$ and $\mathrm{d}=-1.13$, and the equation (2) were subsequently used to calculate monthly average daily sums of diffuse radiation, and the results were compared with measured values. The results of the comparison, employing statistical measures, are presented in Figures 4-6.

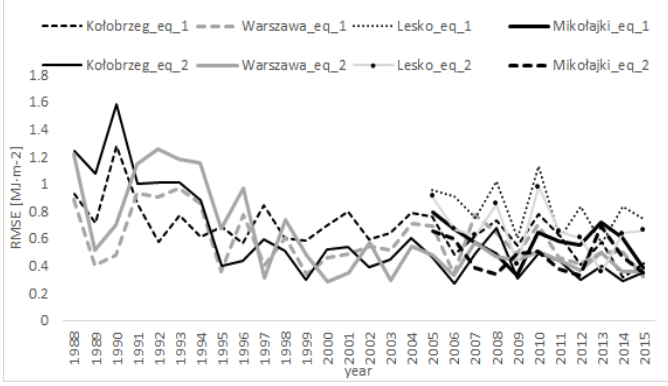

Fig. 4. RMSE for each year (eq_1-equation 1, eq_2equation 2).

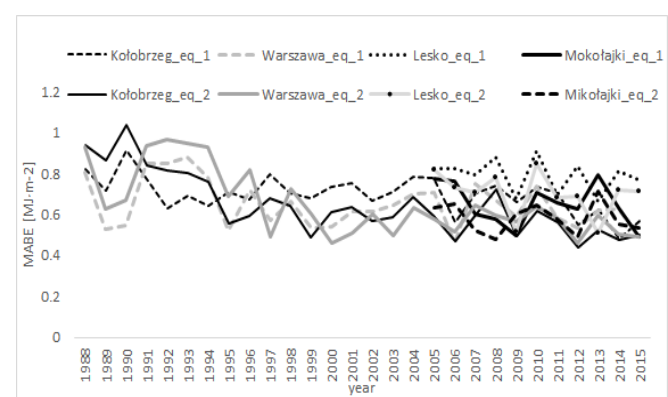

Fig. 5. MABE for each year (eq_1-equation 1, eq_2equation 2).

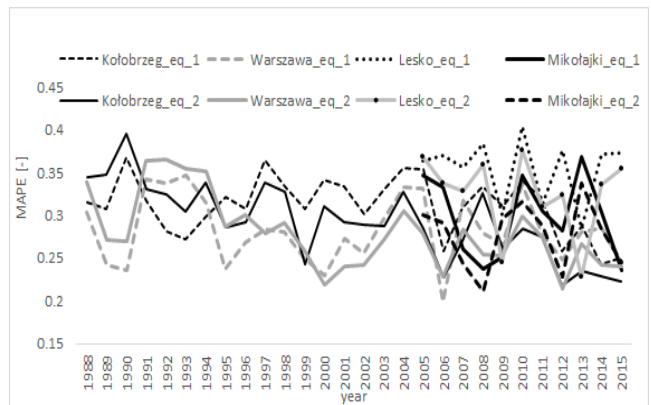

Fig. 6. MAPE for each year

(eq_1-equation 1, eq_2-equation 2).

The calculated values of $\bar{D}$ for both equations (1) and (2) are well fit with the measured data. The both models RSME temporal variability was higher within the period from 1988 to 1997 than in the period 19982015 (Fig. 4). RMSE variability was analysed only for Kołobrzeg and Warsaw stations due to the limited availability of data base for the rest of stations. The values of this error at Kołobrzeg station were in the range from 0.28 to $1.58 \mathrm{MJ} \cdot \mathrm{m}^{-2}$ and from 0.32 to $1.27 \mathrm{MJ} \cdot \mathrm{m}^{-2}$ for equation (2) and Page equation, respectively. The values of RMSE at Warszawa station were found between 0.28 and $1.25 \mathrm{MJ} \cdot \mathrm{m}^{-2}$, and from 0.32 to $0.97 \mathrm{MJ} \cdot \mathrm{m}^{-2}$ for equation (2) and Page, respectively. The temporal variability of RMSE is found reduced in the period 1998-2015 at all four locations and they range between 0.98 and 0.27 $\mathrm{MJ} \cdot \mathrm{m}^{-2}$. Both models performed better within the second part of the 1988-2015 period. There are no noticeable trends of both MABE and MAPE values for both models at all four locations (Fig. 5, Fig. 6). Both equations MABE and MAPE values were found in the ranges $1.04-0.44 \mathrm{MJ} \cdot \mathrm{m}^{-2}$ and $40-20 \%$, respectively.

\section{Summary}

The monthly average daily diffuse solar radiation $(\bar{D})$ for Poland changes from $1.3 \mathrm{MJ} \cdot \mathrm{m}^{-2}$ to $8.2 \mathrm{MJ} \cdot \mathrm{m}^{-2}$ and demonstrates a characteristic annual pattern with a minimum in December and a maximum in June. A spatial gradient in $\bar{D}$ was observed form the north to the south, particularly evident in the cold part of the year. The average share of diffuse radiation in the total solar radiation in Poland is $51 \%$. In the summer it is definitely lower (41\%) and constant in individual months, whereas in the winter it reaches $61 \%$ and is characterised by a greater variability from one month to another. Both the Page's equation, validated for Poland, and the equation calibrated for the available data series from Polish stations demonstrated a very high consistency with actual values of diffuse radiation. The equation proposed for the conditions prevailing in Poland turned out to be more accurate in terms of RMSE, MABE and MAPE, and therefore may be used in the climatological analysis of the distribution of diffuse radiation in Poland The developed model can useful tool for diffuse radiation estimation. The assessments of $\mathrm{D}^{*}$ obtained with this model will support the studies of scattered radiation impact on ecosystem functioning.

\section{References}

1. P. Fu, P.M. Rich, P.M., Comput. Electron. Agr. 37, 25-35 (2002)

2. T.R. Sinclair and T. Horie, Crop Sci. 29, 90-98 (1989)

3. M. Suri, T.A. Huld, E.D. Dunlop, H.A. Ossenbrick, Sol. Energy 81, 1295-1305 (2007)

4. L.M. Mercado, N. Bellouin, S. Sitch, O. Boucher, Ch. Huntingford, M. Wild, P.M. Cox, Nature 458, 1014-1017 (2009)

5. K. Bryś, Zesz. Nauk. AR we Wrocławiu-Inż. Środ. 349, 17-51 (1998)

6. K. Bryś, Sci. Rev. Eng. Env. Sci. 21, 53-62 (2001)

7. A. Kędziora, The basics of agrometeorology (PWRiL, Poznań, 1999) 
8. K. Bryś, T. Bryś T., Zint. Monit. Środ. Przyr. 399408 (2005)

9. M. Wild, J. Geophys. Res. 114 (2009)

10. K Bryś, Dynamics of net radiation balance of grass Surface and bare soil (Wroclaw University of Environmental and Life Science, 2013)

11. D. Matuszko, Int. J. Clim. 23, 228-234 (2014)

12. M. Kleniewska, B.H. Chojnicki, M. Acosta, Meteorol. Hydrol.Water Manage 4(2), 35-40 (2016)

13. M. Kleniewska, B.H. Chojnicki, Acta Geogr. Lodziensia 104, 67-74 (2016)

14. B.Y.H. Liu, R.C. Jordan., Sol. Energy 4, 1-19 (1960)

15. J.K. Page, in: Proceedings of the U.N. Conference on New Sources of Energy 4, S98, 378-390 (1961)

16. J. Podogrocki, Mat. V Sem. Fitoaktynometrii (IUNG, Puławy, 33-39, 1982)

17. M. Iqbal, Sol. Energy 24, 491-503 (1980)

18. D.T. Reindl, W.A. Beckman, J.A. Duffie, SolEnergy 45(1), 1-7 (1990)

19. R Core Team, $R$ : A language and environment for statistical computing (R Foundation for Statistical Computing, Vienna, Austria, 2015);

http://www.R-project.org

20. O. Perpinán, J. Stat. Softw. 50(9), 1-32 (2012)

21. J. Michalsky, Sol. Energy 40, 227-235 (1988)

22. N.A. Elagib, M.G. Mansell, Energy Conv. Manag. 41, 419-24 (2000)

23. M. Yorukoglu, A.N. Celik, Energy Convers. Manage. 47, 2441-50 (2006)

24. S.E. Tuller, Sol. Energy 18, 259-263 (1976)

Diffuse and total solar radiation data were made available by the Institute of Meteorology and Water Management, National Research Institute (IMGW-PIB, www.imgw.pl) and World Radiation Data Centre (http://wrdc.mgo.rssi.ru/). 